\title{
Life Cycle Assessment of Marine Coatings Applied to Ship Hulls
}

\author{
Yigit Kemal Demirel*, Dogancan Uzun, Yansheng Zhang and Osman Turan \\ Department of Naval Architecture, Ocean and Marine Engineering, \\ University of Strathclyde \\ 100 Montrose Street, Glasgow, G4 0LZ, United Kingdom \\ *Corresponding Author (yigit.demirel@strath.ac.uk)
}

\begin{abstract}
This paper presents the methodology developed for Life Cycle Assessment (LCA) of antifouling marine coatings with regards to fouling accumulation on hulls and maintenance of ships. The methodology is based on mathematical models vis-à-vis the environmental and monetary impacts involved in the production and application of hull coatings, added fuel consumption due to fouling accumulation on ship hulls, and hull maintenance. This subject was investigated in a recently completed EU-Funded FP7 Project entitled FOUL-X-SPEL. The LCA methodology was developed using the results of the studies conducted by FOUL$\mathrm{X}$-SPEL Consortium as well as additional data provided by coating manufacturers, shipyards and shipping companies.

Following the introduction of the new LCA model, a case study was carried out to show how to utilize the model using a real tanker which is assumed to be coated with 2 different types of existing coatings, namely a silicone-based fouling-release coating and a tin free self-polishing antifouling paint. The total costs and emissions due to the use of different coating types were calculated for the whole life-cycle of the ship. It has been found that $\mathrm{CO}_{2}$ emission reduction due to mitigation of fouling can be achieved using a silicone-based fouling release coating while reducing the cost by means of fuel cost reductions for the shipowners despite the additional capital expenses. The developed LCA model can help stake-holders determine the most feasible paint selection as well as the optimal hull-propeller maintenance schedules and make condition based maintenance decisions.
\end{abstract}

\section{Keywords}

Life Cycle Assessment (LCA) · Antifouling marine coatings $\cdot$ Fouling $\cdot$ Energy efficiency

Accepted author manuscript of the following research paper: Demirel, Y. K., UZUN, D., Zhang, Y., \& Turan, O (2018). Life cycle assessment of marine coatings applied to ship hulls. In A. Olcer, M. Kitada, D. Dalaklis, \& F. Ballini (Eds.), Trends and Challenges in Maritime Energy Management (Vol. 6, pp. 325-339). (WMU Studies in Maritime Affairs). Cham: Springer Publishing. DOI: 10.1007/978-3-319-74576-3_23 


\section{Introduction}

It is a well-known truth that hull resistance is significant parameter for ships with regards to fuel consumption, increment in power requirement for desired operation capability and Greenhouse gases (GHG) emissions. Basically, ship resistance is divided into two parts, frictional resistance which directly relates to roughness of surface and residuary resistance that occurs because of created waves by ship actions at sea (Demirel 2015).

For low-speed merchant ships frictional resistance is accounted $80-90 \%$ of ship total resistance (van Manen and van Oossanen, 1988). Since the fouling on ships strongly increases the roughness of ship hull surface, fouling is a quite detrimental phenomenon for ship frictional resistance.

In the study done by Wood Hole Oceanographic Institution it was observed the ships in the British Navy have frictional drag increase about $0.25 \%$ and $0.5 \%$ per day for temporal and tropical waters respectively. This led to $35 \%$ to $50 \%$ extra fuel consumption for these ships (Hole 1952).

Fouling organisms' effects on ship resistance is pointed out in respect to their type and coverage rate. According to Schultz (2007) ship resistance is increasing because of fouling in a range between $2-80 \%$ compared to the ship resistance while ship's surface is accepted as clean. In one of recent studies, artificial barnacles printed via 3D printers and attached to plates were towed in towing tank. As a result of experiment for 5\% and $10 \%$ coverage rates $36.8-97.5 \%$ and $22.5-59.7 \%$ increase were observed in respect to bare plates for frictional resistance and effective power respectively (Turan et al. 2016).

To mitigate these detrimental effects of fouling organisms antifouling (AF) paints are widely used for ships all over the world. Thanks to advances in chemistry and material science today the ship industry has the opportunity to use a vast range of antifouling paints. State of art antifouling paints basically are separated into two group, biocide contended Self-Polishing Co-Polymers (SPC) and Foul-Release (FR) antifouling coatings.

Selection of best antifouling paint for any considered ship is not an easy task and related to various parameters such as performance of antifouling paints, operation profile of ship, route etc. An AF coating system can be claimed to be better than another coating system if and only if the total life-cycle costs and environmental impacts of a coating are less than those of the other one. To decide which paint is better than the other one, paints should be evaluated in all their aspects which can be done with the Life-cycle assessment method.

The aim of using the methodology is to quantify the impact of such technology based on improvement on existing ships, as calculated for the remaining life of the ship. This can be extended to fleet-level and global-fleet figures. Actual cost-savings as well as benefit can be established by considering the following points:

- Life cycle costs. 
- Life cycle energy consumption and savings in terms of fuel and cost.

- Potential life cycle environmental impacts in terms of carbon footprint reduction and impact on the marine life.

- Energy and raw material used in each process as well as the waste and emission generated.

- Initial paint cost in terms of material and application.

- Durability of the paint and maintenance cost in terms of frequency of hull cleaning and painting (extended service life).

- Duration of dry-docking/hull cleaning and effect of the paint on the availability of the ship for hire (more income).

The evaluation will consider impacts related to all life cycle stages, by simplifying some of the stages (especially production of AF) and focusing on the effects of AF coatings on fuel consumption of ships during operation and hence emission, and maintenance of ships.

To the best of the authors' knowledge, no specific life cycle assessment model exists to predict the impact of antifouling coatings applied to ship hulls. The aim of this paper is therefore to fill this gap by developing an LCA model consisting of several prediction methods, and to show how to use the proposed LCA model by investigating the effect of the application of two existing marine coatings on the fuel consumption, cost and GHG emissions of a specific real ship over a 30 year of life cycle.

This paper is organized as follows: In Section 2, general LCA method is introduced along with LCA of antifouling coatings. Proposed LCA model is explained in detail by giving mathematical relations that are used in model in Section 3. A case study was carried out to show how to use to the developed LCA model in Section 4. Finally, the results of the study are discussed in Section 5, along with recommendations for future avenues of research.

\section{Methodology}

Since the performance and efficiency of an antifouling (AF) coating can be assessed by its effect on ship fuel consumption due to hull fouling and on maintenance costs and emissions of a ship, the analysis focus on the life cycle of paints on a ship hull rather than focusing on life-cycle of a coating itself. In other words, the AF coating is taken as a system used in the whole life-cycle of a ship and hence the life-cycle of an AF coating system is taken as the whole life-cycle of a ship. The Table 1 depicts these five stages and details the activities and processes partitioned among each stage.

Table 1. Major stages of LCA of an AF coating (Source:Author). 


\begin{tabular}{lll}
\hline \multicolumn{1}{c}{ Stage } & \multicolumn{1}{c}{ Activities } \\
1. Production of AF coatings & $\begin{array}{l}\text { Extraction of natural resources, mining non- } \\
\text { renewable material and transporting these } \\
\text { materials to processing facilities. }\end{array}$ \\
2. Application & $\begin{array}{l}\text { Application of antifouling coatings on ship } \\
\text { hulls. }\end{array}$ \\
3. Operation of ships with AF & $\begin{array}{l}\text { Extra fuel is consumed due to the effects of } \\
\text { antifouling coatings/fouling }\end{array}$ \\
4. Maintenance of ships (Hull & $\begin{array}{l}\text { System maintenance (dry-dock and in water } \\
\text { hull cleaning). } \\
\text { cleaning and recoating) }\end{array}$ & Dismantling of ship \\
5. End of life &
\end{tabular}

Given that a new LCA methodology and model is developed for the assessment of an AF coating, a tailor-made methodology was used to highlight the important parameters of an AF coating. For this reason the LCA results provided in this paper are specific to Anti-Fouling coatings and the methodology does not follow the formal LCA.

\subsection{Data Requirements}

The required data for complete LCA of AF coatings covers an extensive range of information. Therefore, it would be beneficial to split the required information into 2 parts in order to have a better understanding.

\subsubsection{Ship Operations}

The information required in this part is used to estimate the total costs and emissions from fuel consumption of a ship due to the use of different AF coatings. The required data can be listed as below:

- $\quad$ Type of the ship

- Main dimensions of the ship including the wetted surface area

- Sea trial data

- $\quad$ Ship operational data (speed, draft, operational regions and durations of port calls or being stationary)

- $\quad$ Type of the coating on ship hull

\subsubsection{Antifouling Coating Applications}


The information required in this part is used to estimate the total costs and emissions from the activities in the initial and dry-dock paint applications of ships due to the use of different AF coatings. The required data can be listed as below:

- Dry-dock intervals

- Paint related information

- Details of the surface preparation methods

\section{Foul-X-Spel Life Cycle Assessment Model}

The life-cycle model in question is a computer program that aggregates the financial and environmental costs of ship operation and maintenance in relation to fouling. The model captures the aspects of operations and processes that influence and are directly impacted by marine fouling and hence time-dependent drag performances of AF coatings. Figure 1 shows a diagram representing the workflow of FOUL-X-SPEL (Environmentally Friendly Antifouling Technology to Optimize the Energy Efficiency of Ships, Project number 285552, FP7-SST-2011-RTD-1) LCA model. The essential structure of the workflow is that the relevant aspects of the model starting from the shipbuilding stage all the way till the dismantling of the ship is simulated.

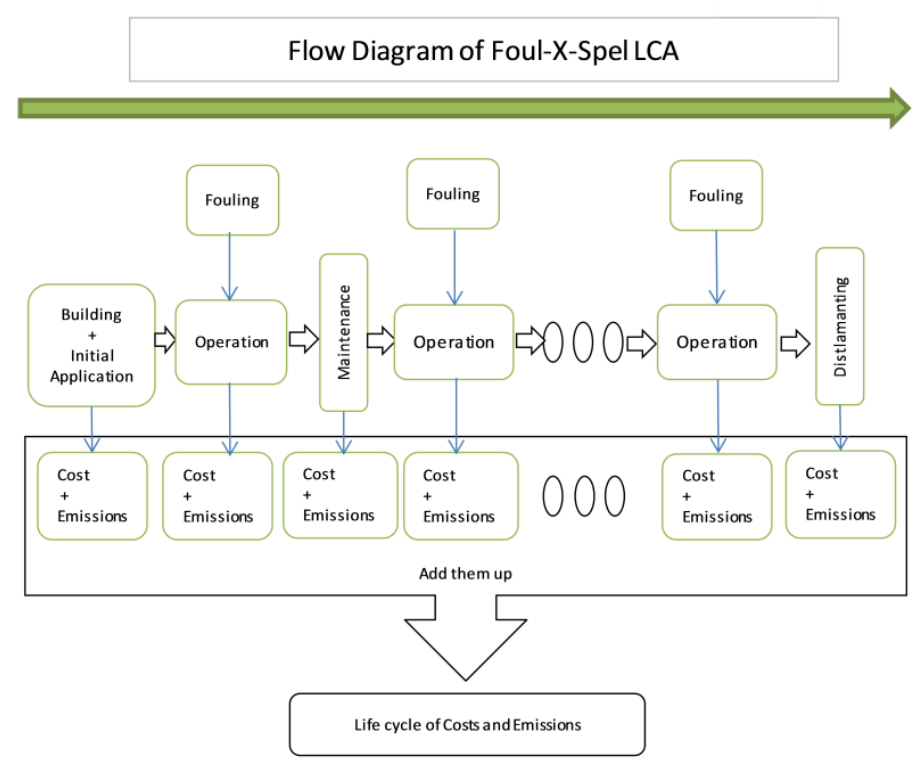

Fig. 1 Schematic diagram of the simulator in FOUL-X-SPEL LCA methodology (Source:Author). 
Fouling primarily accumulates while the ship is static, and rate of growth of fouling depends predominantly on the water temperature. Warmer water is more teeming with life than colder water, and the longer a submerged body stays stagnant in water, the more likely it will be to be colonized by marine flora and fauna. These facts have been well known qualitatively since the beginning of marine transport, however in order to make fine grained decisions about modern anti-fouling measures, we need a quantitative model of these factors. Following are the key ingredients of the model:

1. A representation of voyages and anchorages of the ship in question. The representation should describe the time and location of the ship over its lifetime. The developed model can generate such representations based on probability distributions derived from the operating life of real ships, and can import fully specified voyage data from noon-reports.

2. Model of temperature-dependent and time-dependent growth of fouling.

3. Model of variation of sea-temperature with location.

4. Model of the costs and effects of hull maintenance activities.

5. Model of fuel-consumption behavior of the ship.

These elements come together in a computer program and allow us to evaluate alternative strategies. It must be noted that the drag-coefficient gets re-baselined at the beginning of each maintenance cycle.

The change in drag coefficient is calculated starting from that point. Thus if we identify the $\mathrm{j}$-th voyage of the $\mathrm{i}$-th maintenance cycle using the double index "ij", we could write the overall cost and emissions using the following expression:

$$
\text { Cost }_{\text {total }}=\sum_{i=1}^{N}\left(\operatorname{Cost}_{\mathrm{dry}-\operatorname{dock}(\mathrm{i})}+\sum_{j=1}^{M_{i}}\left(\operatorname{Cost}_{\text {voyage }(i, j)}\right)\right)
$$

Where Cost $_{\text {total }}$ is the total cost over the life cycle. The index "i" runs over the maintenance cycles. Cost $t_{\text {dry-dock(i) }}$ is the cost of the i-th dry dock. Cost $t_{\text {voyage }(i, j)}$ is the cost of the $\mathrm{j}$-th voyage of the $\mathrm{i}$-th cycle. The cost of the voyages may be computed as follows:

$$
\text { Cost }_{\text {voyage }(i, j)}=F_{i} P T_{i j}\left(1+\sum_{k=1}^{j-1}\left(\frac{\Delta C F_{i k}}{C D_{i}}\right)\right)
$$

Where $\mathrm{P}$ is the fuel price, $\mathrm{F}_{\mathrm{i}}$ is the base-line fuel consumption per day at the beginning of the $\mathrm{i}^{\text {th }}$ maintenance cycle, $\mathrm{CD}_{\mathrm{i}}$ is the drag coefficient at the beginning of the 
$\mathrm{i}^{\text {th }}$ maintenance cycle. $\Delta \mathrm{CF}_{\mathrm{ik}}$ is the change in the frictional resistance coefficient in the $\mathrm{k}^{\text {th }}$ anchorage in the $\mathrm{i}^{\text {th }}$ maintenance cycle. Finally $\mathrm{T}_{\mathrm{ij}}$ is the sailing duration of the $\mathrm{j}^{\mathrm{th}}$ voyage in the $\mathrm{i}^{\text {th }}$ maintenance cycle.

Similarly we can express the total emission as follows:

$$
\begin{gathered}
\text { Emission }_{\text {total }}=\sum_{i=1}^{N}\left(\text { Emission }_{\mathrm{dry}-\mathrm{dock}(\mathrm{i})}+\right. \\
\left.\sum_{j=1}^{M_{i}}\left(\text { Emission }_{\text {voyage }(i, j)}\right)\right)
\end{gathered}
$$

Where Emission $_{\text {total }}$ is the total emission over the entire life cycle. Emission $_{\text {dry-dock(i) }}$ is the emissions from the $\mathrm{i}^{\text {th }}$ dry dock. Emission ${ }_{\text {voyage }(\mathrm{i}, \mathrm{j})}$ is the emissions from the $\mathrm{j}^{\text {th }}$ voyage of the $\mathrm{i}^{\text {th }}$ cycle. The emissions from individual voyages may be computed as follows:

$$
\text { Emission }_{\text {voyage }(i, j)}=F_{i} M T_{i j}\left(1+\sum_{k=1}^{j-1}\left(\frac{\Delta C F_{i k}}{C D_{i}}\right)\right)
$$

Most of the terms are in the Emission ${ }_{\text {voyage }}$ expression are common with the corresponding expression for cost. The only different term in the expression is $\mathrm{M}$ which replaces $\mathrm{P}$. M is the mass conversion factor between the fuel and CO2. Please note that the inner summation runs between 1 and $(j-1)$ representing that the fouling accumulation for the $\mathrm{j}^{\text {th }}$ voyage in the cycle is done until the previous anchorage.

\subsection{Fuel Consumption Model}

Fuel consumption over time is strongly dependent on the time-dependent drag performance of antifouling coatings. Once the time dependent drag performance of the antifouling coating and the ship's sea trial information which includes the fuel consumption corresponding to specific speed and draft are known, it is possible to predict the fuel consumption over time.

The fuel consumption depends on several factors. Engine condition, transmission efficiencies and sea-states are significant factors determining the fuel consumption; however in the context of this study we do not have any control over these factors. If the objective was to carry out weather-based routing, the sea-state would be an indispensable part of the model on which to perform the analysis. Likewise if the objective was to plan engine maintenance, the engine's detailed behavior would have to be an integral part of the model. However, in FOUL-X-SPEL LCA model, the focus is on the variation of hull resistance due to the fouling and the surface finish, which allows us to ignore variations in the other aforementioned factors. While ignoring the variations in those factors, some baseline values of those factors are used as scaling parameters. 
Thus we use the baseline values of the ship's drag coefficient and fuel consumption, and linearize the dependence of fuel consumption in the neighborhood of the baseline. The linearized model which is shown at below will allow us to compute the incremental changes caused by the changes in surface fouling.

$$
\Delta F C=F C_{\text {baseline }} * \frac{\Delta C_{F}}{C_{D_{-} \text {baseline }}}
$$

It is of note that the initial baseline values are obtained using the ship details including main dimensions, wetted areas, ship sea trial results etc.

Since fuel consumption is proportional to the drag coefficient, if there is a timedependent model of fouling growth, the linearization is used in conjunction with that model to compute the changes in fuel consumption rates. So a crucial component of the simulation required for FOUL-X-SPEL LCA is the expression of fouling growth as a function of time, given the antifouling coating type. It is well understood that fouling accumulates more aggressively when the ship is stagnant for an extended length of time (Tupper \& Rowson, 2001).

The simulation model must capture this phenomenon in terms of equations or algorithms, but since fouling growth is a complex biological process, the model has to be based upon empirical evidence. In this study, semi-empirical model for fouling were developed based on two substantial investigations. The first investigation was a numerical study of hull surface roughness, which led to the expression of a ship's frictional resistance as a function of the surface roughness. This is a theoretical model which correlates the different hull fouling conditions into frictional resistance (Demirel 2015). In this paper's study, the roughness function values of Schultz and Flack (2007) were used to predict the effect of a range of representative coating and fouling conditions on the frictional resistance of ships, based on the description of surface conditions given by Schultz (2007), using Granville's similarity law scaling procedure (Granville 1987).

The present predictions were made based on the assumptions that the given fouling conditions can be represented by these roughness functions and roughness length scales. Schultz (2007) validated these assumptions and this method by comparing his results with other studies such as Hundley and Tate (1980) and Haslbeck and Bohlander (1992), documenting the effects of coatings and biofouling on ship powering through full-scale trials. Recently, Demirel et al. (2017) used the roughness function values of Schultz and Flack (2007) to predict the effect of biofouling on a ship's resistance using Computational Fluid Dynamics (CFD).

The second investigation was that of long-term immersion of several coated plates in two different oceanic environments accompanied by intermittent measurement of fouling growth on these plates over more than two years. The data from this experiment and the first theoretical method together gave rise to time-dependent formulae for fouling growth for three different coatings and two locations. These formulae culminate in a calculation procedure for obtaining the added resistance coefficient due to fouling. Currently only two locations and three coatings are supported by the time-dependent model but that is only due to the limited nature of the immersion test dataset. The same methodology can be applied to new paints and locations once we plug in experimental results as new data points. 
Although the semi-empirical model developed in this study provide users with a very useful indication of the increase in resistance of a ship due to the use of a specific coating, they may not reflect the resistance increase of ships under real speed-activity conditions since they were developed based on the static immersion data. Hence, this model was calibrated using the real operational data derived from noon data database of Strathclyde University and using the data provided by a paint company.

Developed time-dependent formulation of fouling was derived from immersion experiments. These formulations are based on static immersion experiment done in port waters very close to the land. Our assumption is that such experiments preserve the relative behaviours across different paints of the same type, but the absolute figures of growth rate are not really representative of the fouling growth rate for ships that frequently undergo motion. Thus we used five-year fouling growth rates of two ships under typical operating conditions in order to calibrate the fouling growth equations derived from the immersion experiments.

\subsubsection{Operational Behavior of Ships}

There is no doubt that, the time-dependent drag performances of AF coatings depend on so many operational parameters of a ship along with coatings' own particulars. The most dominant operational parameter is the operational route of the ship which determines geography and the temperature of the waters and the anchorage behavior of a ship. Hence, these parameters must be well defined to be able to calculate accurately the life cycle values. Therefore, an operational behavior prediction sub-model was also developed within the LCA model. The model's approach is for a defined operational behavior of a ship. If the operational behaviors of the ship are defined day-by-day, the time-dependent drag performances are calculated based on the given behavior. This approach is also able to generate the whole life-cycle behavior of a ship using the existing operational data. In other words, for instance if the operational behavior of a ship in the first 2 years is known, the rest of the life cycle behavior of the ship may be assumed to be the same as the first 2 years. It means that, the sub-model is educated using the existing data and it assumes that the behavior of the ship in question is kept the same and the fouling accumulation is estimated based on this assumption.

\subsubsection{Initial and Dry-Dock Paint Application}

The first application of the antifouling coatings and the renewal of the coatings in dry-dock are very important aspects of the life-cycle of an AF coating, because the lifecycle costs and emissions of an antifouling coating system are consequences of the paint application and ship operations. Therefore, the first coating application activities and all the coating related activities in dry-docks are taken into consideration in the model. The model requires the details of such activities as input and then it calculates the total costs of the first application and renewal of the antifouling coatings. The costs may be classified under individual headings, and may be refined to arbitrary level of detail. 
It must be noted that the broken-up costs and emissions are not a necessary condition for the LCA to work. The break-ups are supported because it may be interesting for the stake-holders to understand the individual drivers of cost.

\section{Case Study}

A case study was carried out to show how to use the LCA model using a tanker which is assumed to be coated with 2 different types of coatings, namely a fouling release coating (FoulXSpel 1) and a tin free self-polishing antifouling paint (FoulXSpel 2). A real operating tanker which is around 110000 DWT was selected for this case study. Firstly, the model is validated against the real noon data of the tanker and then the total costs and emissions due to the use of different types of AF coatings are calculated for the whole life-cycle of the ship.

\subsection{Validation}

The validation process involves simulating the life-cycle of a tanker using her 6.6 years trail of noon-reports and comparing the behavior against the simulation. The simulated result was within $1.65 \%$ of the actual value. Figure 2 is a plot showing the actual fuel consumed against simulated values.

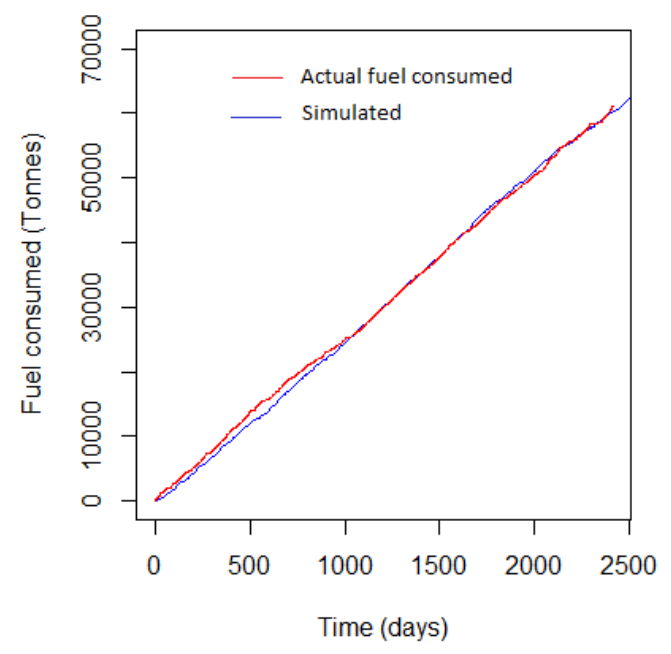

Fig. 2 Actual fuel consumed against simulated values (Source:Author). 


\subsection{Results}

The production of the paint generates emissions indirectly due to the energy consumption and refining the raw materials to the atmosphere due to the use of energy and raw materials. However, only the emissions due to electricity consumption are taken into consideration as output for this LCA. It is assumed that the paints are produced using the purchased electricity and the conversion factor of $0.53936 \mathrm{kgCO}_{2} / \mathrm{kWh}$ is assumed according to Defra and DECC (2010). Besides, the selling rate to ship owner is taken into consideration since the life cycle costs are to be also evaluated.

The activities in initial and dry-dock paint application require energy inputs and have corresponding emissions that impact the environment and human health. The emissions occurred due to these energy inputs are also ignored due to the lack of the data. The costs of each action of the initial and dry-dock paint application stage as well as the paint costs, on the other hand are considered. Major differences between the maintenance actions of the ship coated with FoulXSpel 2 and that of coated with FoulXSpel 1 are taken into consideration.

Another input is the heavy fuel oil (HFO) used during the sailing of the ship and it is the most important parameter, if the amount of the consumed HFO is taken into account for the operation of the ship. It is of note that the time-dependent drag performances of different coatings may differ significantly due to the ship type and operational region and it directly affects the amount of the consumed HFO dramatically.

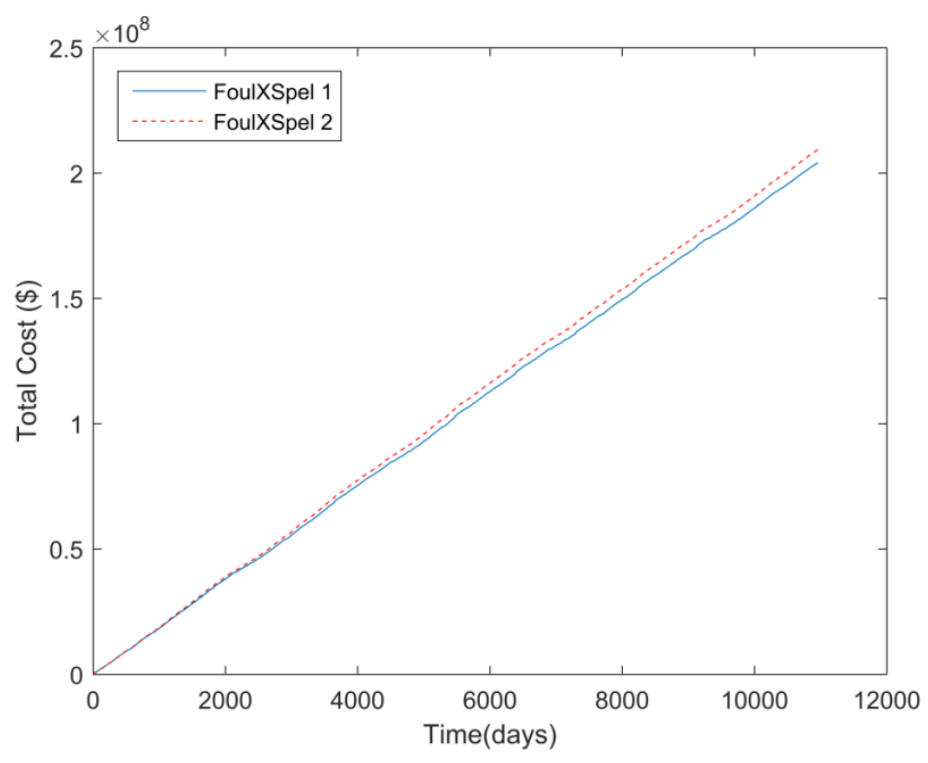

Fig. 3 Comparison of total costs of FoulXSpel 1 and FoulXSpel 2 (Source:Author). 


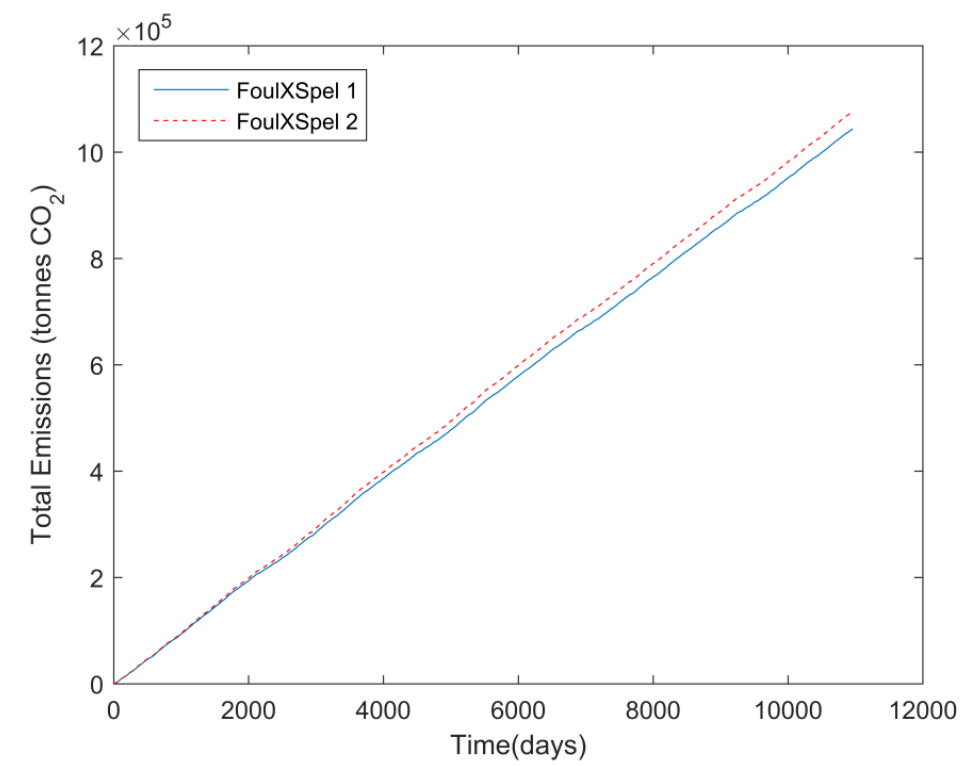

Fig. 4 Comparison of total emissions of FoulXSpel 1 and FoulXSpel 2 (Source:Author).

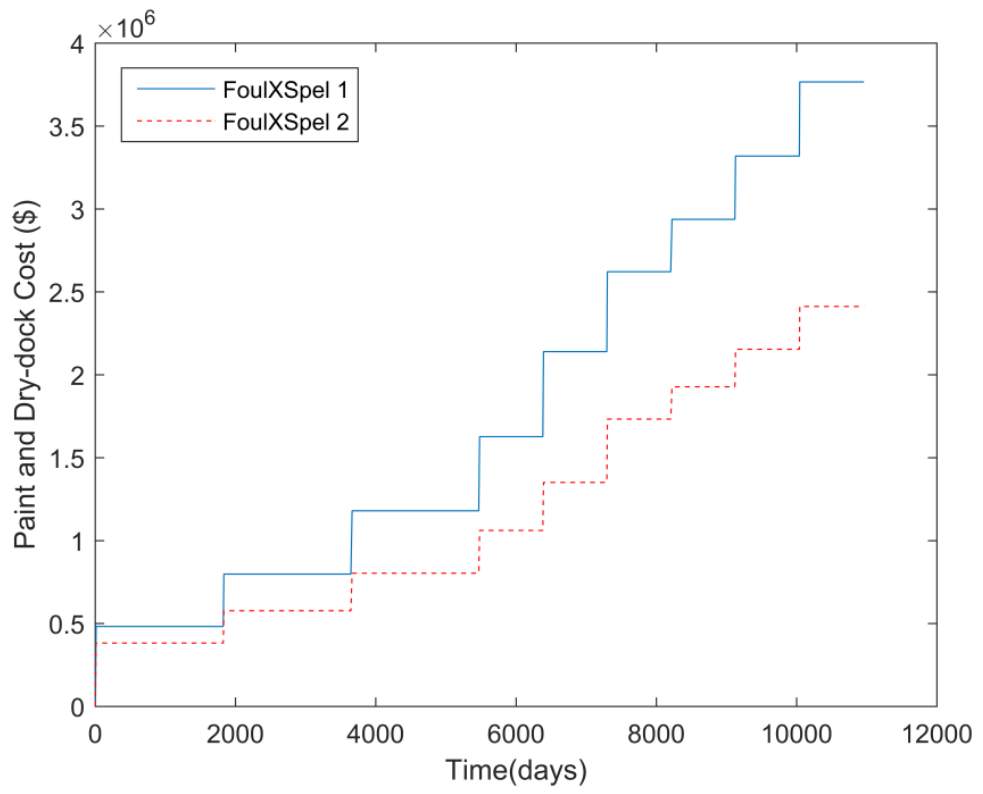


Fig. 5 Comparison of total paint and maintenance costs of FoulXSpel 1 and FoulXSpel 2

(Source:Author).

Figures 3 and 4 compare the overall cost and emission categories of ships coated with FoulXSpel 1 and FoulXSpel 2 over 30 years of life cycle. It's clearly seen in Figure 5 FoulXSpel 1's initial and maintenance costs are much higher when compared with those of FoulXSpel 2, but the use of fouling release coatings, e.g. FoulXSpel 1, compensates its high investment costs in terms of fuel savings with respect to the self-polishing AF, e.g. FoulXSpel 2, as evidently shown in Figure 3. Besides, the total emissions due to the use of FoulXSpel 1 are much less than those of FoulXSpel 2 as depicted in Figure 4. It can be translated into a harmful effect of self-polishing AF in terms of $\mathrm{CO}_{2}$ emissions along with the other harmful effects on marine environment such as releasing biocides.

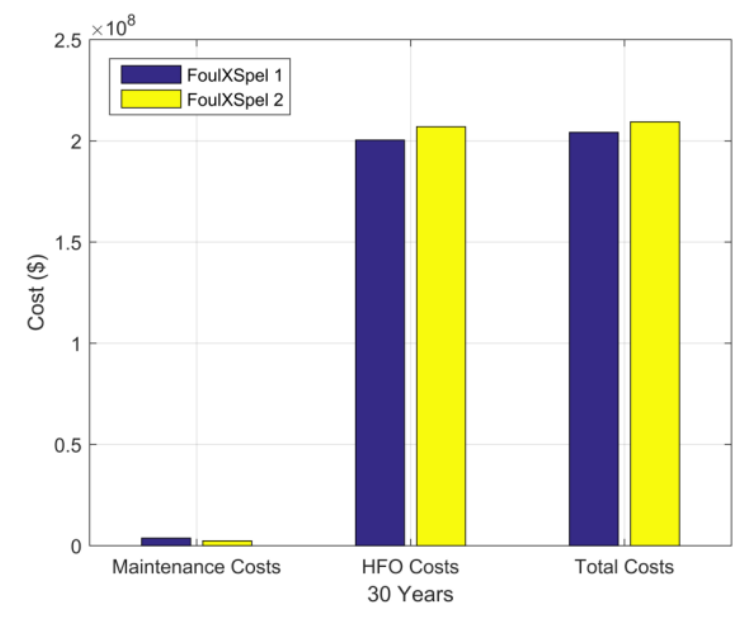

Fig. 6 Overall cost categories over 30 years (Source:Author). 


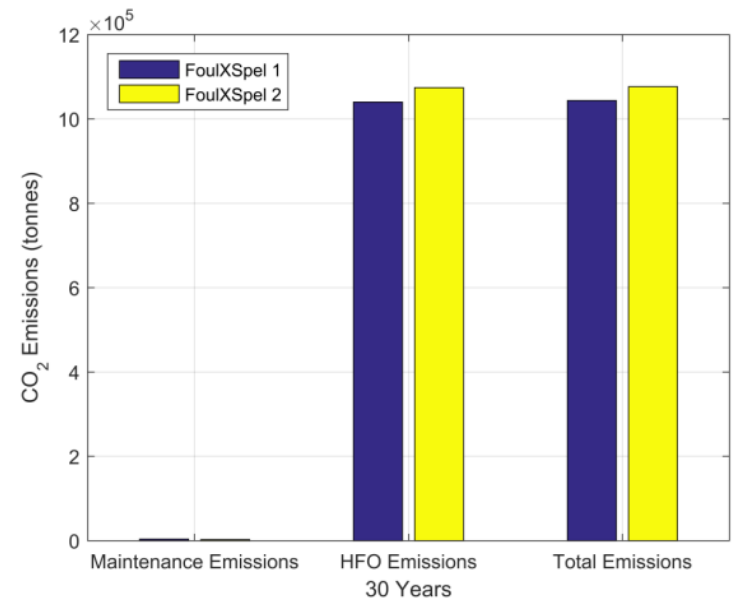

Fig. 7 Overall emission categories over 30 years (Source:Author).

Figures 6 and 7 compare the overall cost and emission categories of ships coated with FoulXSpel 1 and FoulXSpel 2 over 30 years of life cycle. It is evidently seen from Figures 6 and 7 that, initial and dry-dock paint application (maintenance) costs and emission are much less than the cost and emission from HFO. The assessment reveals the differences between these coatings and highlights the advantages of fouling release coatings against self-polishing coatings. The use of FoulXSpel 1 provides a $2.5 \%$ saving of costs and a $3 \%$ saving of $\mathrm{CO}_{2}$ emissions with respect to the use of FoulXSpel 2, in total over 30 years for this particular ship.

\section{Conclusion and Discussion}

A new Life Cycle Costs and Environmental Impact Assessment model was developed for the assessment of AF coatings with regard to the life-cycle of a ship. For this reason, a new methodology is also proposed within the model. The most important difference which makes this model novel is that all existing LCA models rely on fuel consumption data that daily recorded in noon reports whereas proposed model made a prediction of fuel consumption through using static and dynamic paint experiments before ship launches to sea. It should be kept in mind that noon reports include many effects that affect fuel consumption of ship such as the weather conditions, main engine performance and transmission system. Therefore creating a LCA system by introducing these non-target effects would not provide a biofouling prediction based LCA model as proposed this model within this study.

Firstly, the parameters affected by the use of AF coatings were investigated and all the relevant items were selected. The required data to assess the AF coatings are defined. Since the assessment of an AF coating over a life-cycle is not a straightforward procedure, various modelling techniques were used to predict the time-dependent drag 
performances of different AF coatings. The semi-empirical formulae developed in this study were calibrated using the real operational data of various ships. By this way, the real time dependent-drag performances of AF coatings under speed-activity conditions were modelled. Afterwards, a sub-model was developed to predict the operational behaviour a ship in her life-cycle using either real operational data of a ship.

The costs and emissions due to the initial and dry-dock paint applications are modelled using the real dry-dock reports. This data clearly reveals the major differences between the application methods of fouling release and self-polishing AF coatings. All the differences are also considered in the model. Finally, a generic LCA model for the assessment of AF coatings are developed gathering all the sub-models and input data. The model was then validated against the 6.6 years of real operational data.

Then, a case study was carried out to show an example of LCA of two different AF coatings, namely a fouling release coating (FoulXSpel 1) and a self-polishing AF (FoulXSpel 2).

This model can be used as a decision making tool which determines the suitable coating type for particular types of ships. It may also be used to decide the best maintenance and/or hull cleaning activities and/or intervals. Techno-economic feasibility study of a new developed AF coating can be carried out using this LCA model.

\section{References}

Defra \& DECC (2010) Guidelines to Defra / DECC's GHG Conversion Factors for Company Reporting: Methodology Paper for Emission Factors. http://archive.defra.gov.uk/environment/business/reporting/pdf/101006guidelines-ghg-conversion-factors-method-paper.pdf. Accessed 30 July 2014

Demirel YK (2015) Modelling the Roughness Effects of Marine Coatings and Biofouling on Ship Frictional Resistance. Dissertation, University of Strathclyde

Demirel YK, Turan, O \& Incecik A (2017). Predicting the effect of biofouling on ship resistance using CFD. Applied Ocean Research, 62, pp.100-118. Available at: http://dx.doi.org/10.1016/j.apor.2016.12.003.

FOUL-X-SPEL (2011) FOUL-X-SPEL : Environmentally friendly antifouling technology to optimize the energy efficiency of ships. http://www.foulxspelantifouling.com/.Accessed 01 February 2017 
Granville PS (1978) Similarity-law characterization methods for arbitrary hydrodynamic roughnesses. Final Report Naval Ship Research and Development Center, Bethesda, MD Ship Performance Dept. 1978;1.

Haslbeck EG, Bohlander G (1992) Microbial biofilm effects on drag-lab and field. 1992 Ship Production Symposium Proceedings, SNAME1992.

Hole W (1952) Marine Fouling and Its Prevention Bureau of Ships, Navy Department. , (580).

Hundley L, Tate C (1980) Hull-fouling studies and ship powering trial results on seven FF 1052 class ships. D W Taylor Naval Ship Research and Development Center Report \# DTNSRDC-80/027 111 p. 1980.

Schultz MP (2007) Effects of coating roughness and biofouling on ship resistance and powering. Biofouling, 23(5-6), pp.331-41. Available at: http://www.ncbi.nlm.nih.gov/pubmed/17852068.

Schultz MP, Flack K (2007) The rough-wall turbulent boundary layer from the hydraulically smooth to the fully rough regime. Journal of Fluid Mechanics. 2007;580:381-405.

Tupper EC, Rawson KJ (2001) Basic Ship Theory, Combined Volume, Butterworth Heinemann.

Turan $\mathrm{O}$ et al, (2016) Experimental determination of added hydrodynamic resistance caused by marine biofouling on ships. Transportation Research Procedia, 14(0), pp.1649-1658. Available at: http://dx.doi.org/10.1016/j.trpro.2016.05.130.

Van Manen JD, Van Oossanen(1988) P. Resistance. In: Lewis EV, editor. Principles of Naval Architecture Second Revision: Volume II: Resistance, Propulsion and Vibration. The Society of Naval Architects and Marine Engineers, Jersey City, NJ; 1988. 